\title{
Tecnologias digitais e as práticas pedagógicas dos professores de MATEMÁTICA da Educação Básica
}

DOI: 10.23864/cpp-v1-n1-66

\author{
Patrícia Sândalo Pereira \\ Susimeire Vivien \\ Rosotti de Andrade
}

\section{Resumo}

Este artigo tem como base um estudo desenvolvido na formação continuada de professores que atuam na Rede Estadual de Ensino pertencente ao Núcleo Regional de Educação de Foz do Iguaçu. O objetivo principal deste estudo foi investigar as vozes dos professores em relação aos limites e às possibilidades de utilização da webquest em sua prática pedagógica. Neste estudo, compreendemos a formação continuada como um fator primordial para os profissionais entenderem a responsabilidade do trabalho docente, com o intuito de favorecer um diálogo, no qual todos são parceiros críticos da formação. A coleta de dados foi realizada por meio de questionário e observação de campo. Os sujeitos da pesquisa foram quarenta e dois professores que atuam na Rede Estadual de Ensino pertencente ao Núcleo Regional de Educação de Foz do Iguaçu. Como metodologia de análise, utilizamos a Análise Textual Discursiva. Pudemos constatar com esta pesquisa que os professores, apesar de serem receptíveis e sentirem-se motivados com a webquest, apontam como dificuldades, na utilização em sua prática pedagógica, os seguintes motivos: o tempo necessário para a preparação e a estrutura física (laboratório) disponível nas escolas. Além disso, observamos que os professores entendem que as TDIC precisam ser aproximadas da escola, visto que são meios que chegaram e têm potencialidades de contribuir com o desenvolvimento educacional.

Palavras chave: Formação Continuada. Educação Básica. Prática Pedagógica. Webquest. 


\title{
Digital technologies and educational practices of math teachers of basic education
}

\author{
Patrícia Sândalo Pereira \\ Susimeire Vivien \\ Rosotti de Andrade
}

\section{Abstract}

This article is based on a study conducted in the continuing education of teachers who work in the Education State Network belonging to the Regional Education Center of Foz do Iguaçu. The aim of this study was to investigate the voices of teachers in relation to the limits and possibilities of use of the webquest $i$

$\mathrm{n}$ their practice. In this study, we understand the continuing education as a key factor for professionals understand the responsibility of teaching, with a view to promoting a dialogue in which all partners are critical training. Data collection was conducted through a questionnaire and field observation. The subjects were forty-two teachers who work in the Education State Network belonging to the Regional Education Center of Foz do Iguaçu. As analysis method, we use the Text Analysis Discourse. We observed this research that teachers, even though they are receptive and feel motivated to webquest, point to difficulties in use in their practice, the following: the time needed for the preparation and the physical structure (laboratory) available in schools. Moreover, we observed that teachers understand that TDICs must be approximated the school, as they are means to come and have the potential to contribute to the educational development.

Keywords: Continuing Formation; Basic Education; Teaching Practice; Webquest. 


\section{Introdução}

As Tecnologias Digitais modificam nossas vidas, favorecendo novas maneiras de comunicação, trabalho e pensar. Neste sentido, a escola tem responsabilidade de oportunizar e familiarizar a futura geração com as novas Tecnologias Digitais de Informação e Comunicação - TDIC, pois, como aponta Fichtner (2012), nas sociedades modernas, a escola é considerada uma instituição social que mais se expande e onde as crianças e jovens passarão o tempo de suas vidas que são considerados como o mais produtivo e criativo.

Fullan e Hargreaves (2001) sublinham ainda que os professores são os principais responsáveis no processo de ensino e aprendizagem neste ambiente. Atualmente, são os que mais influenciam no desenvolvimento das crianças e jovens, portanto, são fundamentais na formação das gerações futuras.

No entanto, pesquisadores como Marco (2009) apontam que a demanda da sociedade por uma formação que prepare o futuro professor para usar as novas tecnologias na escola existe e ainda não foi atendida pelos cursos de licenciatura em Matemática. Dessa forma, ao tratar da formação para uso das TDIC, cumpre-nos expor nosso entendimento sobre ela. Pressupomos que tal formação consiste em aprender Matemática usando o computador como ferramenta para a construção de conhecimento, corroborando o que defende Valente (1999).

Em outras palavras, trata-se de aprender com o computador e não somente sobre ele. Mais do que isso: trata-se de aprender a ensinar com o computador, em situações que tenham como proposta ensinar a Matemática, usando tecnologias a partir de uma abordagem pedagógica que não consista apenas na virtualização do ensino tradicional (VALENTE, 1999; MARCO, 2009).

Desse modo, a formação continuada destes profissionais deve ser um espaço rico para problematizar discussões e aproximações das TDIC. Como aponta Imbernón (2009, p.72), a formação deve contribuir para gerar um "conhecimento profissional ativo e não passivo".

Frente a este contexto, propusemo-nos a investigar as vozes dos professores em relação aos limites e às possibilidades de utilização da webquest em sua prática pedagógica, pois notase que ainda é complexo para o docente integrá-las à sua prática pedagógica, como aponta Moraes (2013), [...] a grande maioria dos professores ainda continua privilegiando a velha maneira com que foram ensinados, reforçando o velho ensino, afastando o aprendiz do processo de construção do conhecimento (MORAES, 2013, p. 58).

\section{As tecnologias digitais de informação e comunicação (TDIC) na Educação Básica}

O conceito usual do termo tecnologias, de acordo com Kenski (2003), é para referendar as ferramentas que auxiliam as pessoas a viverem melhor dentro de um determinado contexto 
histórico, e elas acompanham o homem desde os primórdios da civilização. No entanto, Veraszto et al. (2008) destacam que:

A tecnologia exige um profundo conhecimento do porquê e do como seus objetivos são alcançados, se constituindo em um conjunto de atividades humanas associadas a um sistema de símbolos, instrumentos e máquinas (VERASZTO et al., 2008, p. 69).

Dessa forma, as tecnologias possibilitam construir obras, bem como fabricar produtos, utilizando conhecimentos científicos.

Bazzo et al (2003) corroboram com essa constatação e esclarecem que utilizam o termo técnica para determinar as habilidades, os procedimentos, os artefatos desenvolvidos sem a ajuda do conhecimento científico, mas quando utilizamos o termo tecnologia significa que nos referimos aos sistemas desenvolvidos, levando em conta o conhecimento científico.

Os autores destacam ainda que esta análise sobre a definição de tecnologia favorece um discurso crítico sobre sua inserção na sociedade moderna, analisando seus benefícios, mas também os riscos que ela pode causar, visto que esta visa atender ao sistema capitalista ${ }^{13}$ vigente.

As tecnologias tais como: a televisão, o vídeo, o cinema, o computador, o telefone, o fax e a internet modificaram nossos hábitos. Assim, precisamos ter uma atitude prudente em relação a sua utilização, de modo que não nos tornemos reféns delas. Vale dizer que todas estas mudanças que ocorrem fora do contexto escolar acabam refletindo também neste ambiente social, e os professores devem, assim, questionar seu posicionamento relacionado a inclusão das TDIC-na escola.

Hoje, do seu computador, o professor pode corrigir, pelo menos virtualmente, os trabalhos dos seus alunos, preencher um boletim de notas, pagar contas no banco, escrever aos amigos, ouvir música, consultar o horário de chegada de um trem, reservar um quarto no hotel e até ver, ao vivo, os últimos movimentos de um astronauta no espaço ou as imagens de uma sonda enviada para marte (KARSENTI, 2012, p.335).

O autor acrescenta que, especificamente na educação, o aspecto mais impactante foi o crescimento surpreendente da internet, que mudou de maneira decisiva os hábitos e a comunicação da sociedade moderna. Assim, a escola não pode ignorar a contribuição das TDIC no desenvolvimento educacional e, caso o faça, terá sua imagem comprometida, sendo vista como desnecessária à sociedade moderna.

13 Como aponta Gentili (2008), no sistema capitalista, há utilização de discursos "transformação educacional” para minimizar as situações precárias da educação pública que, em alguns casos, no Brasil, há escolas que nem energia elétrica possuem. Este sistema também responsabiliza os professores pela profunda crise dos sistemas escolares, pelas taxas de repetência, pela violência dentro e fora da escola e pela falta da participação cidadã nas questões mais relevantes que a sociedade deve enfrentar.

ISSN 2526-2882

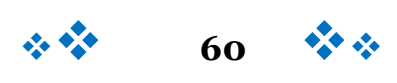


Como destaca Libâneo (2004), não resta dúvida que a escola continuará a utilizar o quadro-negro e os cadernos. Entretanto, os professores não podem negar que "há tempos o professor e os livros didáticos deixaram de ser as únicas fontes do conhecimento. Ou seja, professores, alunos, pais, todos precisamos aprender a ler sons, imagens, movimentos e a lidar com eles”. (LIBÂNEO 2004, p.39-40).

Portanto, de acordo com Porto (2006), é fundamental que a escola insira [...] as informações presentes nas tecnologias as próprias ferramentas tecnológicas, articulando-as com os conhecimentos escolares e propiciando a interlocução entre os indivíduos (PORTO, 2006, p.44). Ponte e Oliveira (2001) também argumentam que:

[...] através das Novas Tecnologias é possível dar uma visão da Matemática mais suave, de modo que os alunos se sintam mais motivados para "descobrir" matemática, visto que hoje em dia qualquer jovem pode ter acesso a um computador. As Novas Tecnologias na escola podem vir a facilitar todo o processo de ensino-aprendizagem na medida em que permitem um leque muito vasto de exploração, visualização e experimentação que de outra forma seria praticamente impossível (PONTE; OLIVEIRA, 2001, p. 15).

A fala dos autores permite afirmar que a escola está sofrendo pressão da sociedade para utilizar as TDIC em seu ambiente e a familiarização dos estudantes na sociedade atual com elas, especificamente com a utilização do computador, indicam um fator como positivo no desenvolvimento educacional dos estudantes.

O professor deve ser um profissional engajado que compreende a sua responsabilidade na formação de cidadãos críticos, visto que muitos alunos terão acesso a estas tecnologias somente neste ambiente social. Diante de todas as mudanças ocorridas, este profissional deve entender que sua função não é de um mero transmissor do conteúdo, seu papel vai muito além, ou seja, vai ao encontro de um professor que entende que seu papel é de um mediador do conhecimento.

Diante das colocações acima, apresentaremos a seguir a metodologia denominada Webquest que favorece o trabalho de autoria dos professores, à medida que planejam o uso da Internet na educação e a produção de materiais pedagógicos, e promove e amplia as formas de acesso à informação via Internet de maneira orientada.

\section{O que é uma Webquest}

O termo Webquest foi criado por Bernard Dodge e Tom March para designar tipos de atividades que consistiam na utilização da Word Wide Web para fins educativos. A Webquest propõe atividades voltadas para a pesquisa, com a informação disponibilizada parcial ou totalmente na Web. 
Segundo Dodge (1995), a Webquest pode ser definida como:

[...] uma metodologia de pesquisa na Internet, voltada para o processo educacional, estimulando a pesquisa e o pensamento crítico. É um formato de lições como qualquer outro, não requer nenhum software especial apenas a habilidade de criar web pages. É uma lição com estrutura, como qualquer outra, mas o fundamental dela é que está apresentado em tarefas executáveis e interessantes e que sejam próximas do dia a dia do aluno (DODGE, 1995).

Com a teorização do autor, podemos afirmar que a Webquest é, uma pesquisa sob orientação, onde algumas ou todas as informações com as quais os alunos terão acesso originam-se de recursos da Internet. Dessa forma, o professor tem a possibilidade de orientar e selecionar as informações para os alunos ter acesso às fontes confiáveis, bem como pertinentes ao tema a ser trabalhado.

A Webquest é constituída pelos seguintes componentes: introdução, tarefa, processo, recursos ou fontes, avaliação e conclusão. Existem outras formas, mas todas têm os componentes principais: introdução, tarefa, avaliação e conclusão.

A introdução é uma das partes principais da Webquest, pois ela é a porta de entrada, e onde se deve seduzir os alunos, para logo que leiam a introdução desperte um desejo ou interesse de realizar as tarefas propostas pela Webquest.

Seguidamente, a tarefa é a parte que mais exige tempo, dedicação e criatividade do autor, porque ele terá que criar algo que motive o aluno e ao mesmo tempo seja desafiadora e possível de ser realizada. Sendo assim, a tarefa é considerada a parte mais difícil na hora de confeccionar uma Webquest.

Indo além na construção da Webquest, temos a avaliação que deve indicar os critérios que serão adotados para avaliar o desempenho dos alunos. Novamente fica indicada a responsabilidade do professor, que pode avaliar apenas o resultado final da questão ou seu desenvolvimento no decorrer da mesma.

Finaliza-se a construção da Webquest com a conclusão, onde deve aparecer um resumo descrevendo o desenvolvimento e as vantagens da realização deste trabalho, a qual deve ser bem clara, breve e simples, resumindo o propósito geral da sua Webquest. Para concluir a Webquest, é importante realçar a importância do tema tratado e indicar caminhos que possam estimular os alunos a prosseguir na investigação sobre o tema.

Portanto, a Webquest pode ser vislumbrada como uma alternativa propícia para o enriquecimento da prática pedagógica dos professores.

A seguir, destacaremos a relevância da formação continuada como favorável para inserção das TDIC na sala de aula, pois sabemos que, para que isso aconteça, é necessário o envolvimento dos professores. 


\section{A formação do professor e sua importância no contexto escolar como um mediador da utilização das tecnologias digitais}

Ao tratar do tema de utilizações de tecnologias na educação, $\mathrm{D}^{\prime}$ Ambrósio (2006) salienta que muito se fala que as diferentes inovações tecnológicas poderão substituir os professores, mas nada os substituirá. Todas são meios auxiliares que contribuem no desenvolvimento educacional, pois proporcionam uma maior interação com seus alunos, vislumbrando a produção crítica de novos conhecimentos.

No entanto, o autor destaca que o professor que insistir em acreditar que sua função é de um mero transmissor de informação está caminhando para a substituição, pois a sociedade moderna exige que este profissional seja um gerenciador que media o processo de aprendizagem e promove uma interação com os alunos na produção crítica de novos conhecimentos.

Libâneo (2002) corrobora com esta afirmação e compreende que:

O ensino exclusivamente verbalista, a mera transmissão de informações, a aprendizagem entendida somente como acumulação de conhecimentos, não subsistem mais. Isso não quer dizer abandono dos conhecimentos sistematizados da disciplina nem da exposição de um assunto. O que se afirma é que o professor medeia a relação ativa do aluno com a matéria, inclusive com os conteúdos próprios de sua disciplina, mas considerando os conhecimentos, a experiência e os significados que os alunos trazem à sala de aula, seu potencial cognitivo, suas capacidades e interesses, seus procedimentos de pensar, seu modo de trabalhar. Ao mesmo tempo, o professor ajuda no questionamento dessas experiências e significados, provê condições e meios cognitivos para a sua modificação por parte dos alunos e orienta-os intencionalmente para objetivos educativos. [...] É nisso que consiste ajuda pedagógica ou mediação pedagógica (LIBÂNEO, 2004, p. 29).

A fala do autor destaca o papel principal do professor no processo de ensino e aprendizagem ${ }^{14}$. Dessa forma, estes profissionais são, sim, responsáveis na inserção das inovações existentes na sociedade.

Karsenti (2012) traz outras contribuições a esse debate ao enfatizar que o problema da inclusão das tecnologias no ambiente educacional está relacionado aos problemas materiais. Mas, o ponto crucial é que a inclusão somente ocorrerá com uma mudança drástica na prática pedagógica dos professores, porém é imprescindível que isto aconteça, pois as tecnologias,

[...] facilitam o acesso a uma cultura geral rica e extensa. Elas também permitem a aquisição de um grande número de competências, entre as quais a capacidade de síntese e de análise. As diferentes fontes de informação

\footnotetext{
${ }_{14}$ Segundo Libâneo (2012, p.43), "o ensino e aprendizagem formam uma unidade dentro de um mesmo
} processo, ainda que cada termo guarde sua especificidade, não podendo ser subsumido um no outro”.

ISSN 2526-2882

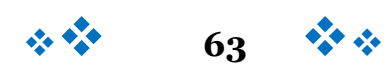


disponíveis na internet ajudam os alunos a aguçar o seu rigor intelectual e moral. [...] também produzem uma motivação, uma determinação e um gosto sem precedentes entre os alunos (KARSENTI, 2012, p.344).

Assim, não é possível pensar na inserção dessas diferentes ferramentas sem pensar na formação dos professores, pois ela deve aproximar os professores das TDIC, oportunizando discussões de pesquisas e problematizando junto aos seus pares os desafios e as possibilidades da integração delas à sua prática pedagógica.

Por outro lado, a escola e suas práticas pedagógicas são entendidas por Franco (2012) como sendo práticas sociais, que são exercidas com a finalidade de concretizar os processos pedagógicos, apresentam dificuldade na inserção das TDIC, visto que estas devem ser acompanhadas, sobretudo, de questionamentos, entre eles: Como utilizar de maneira pedagogicamente adequada, pois os professores "sozinhos não transforma a sala de aula; as práticas pedagógicas funcionam como espaço de diálogo: ressonância e reverberação das mediações entre a sociedade e sala de aula" (FRANCO, 2012, p. 162).

Como afirma Franco (2012), as práticas pedagógicas não são mudadas pelos professores por decretos, mas somente se estes profissionais considerarem como necessário. "Ou seja, o professor, ao construir sua prática pedagógica, está em contínuo diálogo com o que faz, por que faz e como deve fazer" (FRANCO, 2012, p. 186).

Dessa forma, uma prática é considerada prática pedagógica à medida que o professor consegue estabelecer uma reflexão de seu trabalho de forma crítica. Entendemos que isso não é algo exercido de forma trivial, pois são vários os fatores externos que o comprometem.

Nesta perspectiva, não é suficiente a disposição ou a utilização das TDIC nas escolas, mas sim que os profissionais deste ambiente social desenvolvam um posicionamento crítico sobre seus impactos na sociedade moderna, refletindo sobre a sua utilização, ou seja, "fazer uma educação para a mídia, para ensinar os jovens a dominar a linguagem televisual, para não serem dominados por ela”. (LIBÂNEO, 2004, p. 71)

$\mathrm{O}$ autor ressalta que a formação inicial e a formação continuada são fatores que possibilitam aos professores entenderem de forma crítica as tecnologias, mas as universidades brasileiras não propiciam aos futuros professores as condições adequadas para exercerem sua profissão, nem cultura geral necessária para entender a sociedade em que vivem. E a formação continuada é escassa e, quando proposta, não os motiva a participar.

Diante disso, eles sentem-se desvalorizados e não se envolvem nas propostas, mesmo quando são obrigados a participar. Assim, a formação de professores em atividade deve ser um espaço de diálogo, no qual estes profissionais são considerados como sujeitos possuidores de conhecimentos e são valorizados nas discussões problematizadas, utilizando-se as teorias.

Segundo Imbernón (2009), 
A formação deve apoiar-se em uma reflexão dos sujeitos sobre sua prática docente, de modo a lhes permitir examinar suas teorias implícitas, seus esquemas de funcionamento, suas atitudes etc., realizando um processo constante de auto-avaliação que oriente seu trabalho. (IMBERNÓN, 2009, p.55).

Diante das colocações apresentadas anteriormente sobre a importância da formação continuada dos professores, como possibilidade deles integrarem as TDIC em sua prática pedagógica, vamos apresentar, a seguir, os resultados de uma pesquisa desenvolvida com professores de Matemática.

\section{Metodologia de pesquisa e sujeitos}

A metodologia tem como objetivo favorecer ao pesquisador traçar caminhos para sua pesquisa e ela pode ser vislumbrada como "as atividades práticas necessárias para a aquisição dos dados com os quais se desenvolverão os raciocínios que resultarão em cada parte do trabalho final" (SANTOS, 2007, p. 88)

Esta pesquisa teve como objetivo investigar as vozes dos professores em relação aos limites e às possibilidades da integração da metodologia webquest em sua prática pedagógica. Essa metodologia é de natureza qualitativa e interpretativa. De acordo com Ludke e André (1986), as pesquisas em educação são de natureza qualitativa, pois elas não possibilitam a mensuração dos dados, apenas a interpretação de dados de uma forma mais ampla.

Os sujeitos da pesquisa foram quarenta e dois professores que atuam na Rede Estadual de Ensino pertencente ao Núcleo Regional de Educação, sendo 23 de Foz do Iguaçu e 19 de São Miguel do Iguaçu, que participaram de uma proposta de formação continuada desenvolvida pelas proponentes deste artigo.

Para realização da proposta de formação continuada, primeiramente, realizou-se uma parceria com o Núcleo Regional de Educação, que possibilitou o desenvolvimento dos encontros na hora atividade destes profissionais da educação. Os encontros foram realizados em um Colégio Estadual escolhido pelos professores dos municípios atendidos.

Solicitamos à equipe de ensino de Matemática do Núcleo Regional de Educação os emails dos professores que participariam para que, dessa forma, eles fossem cadastrados no site PhpWebquest da EscolaBR, visto que, depois de cadastrados, haveria uma espera de, no máximo, 24 horas, para receber o e-mail da autorização da conta do usuário.

A coleta de dados foi realizada utilizando como instrumentos a observação e um questionário. Como metodologia para análise dos dados, utilizamos a análise textual discursiva. Conforme Moraes e Galiazzi (2011), sua realização ocorre seguindo os seguintes passos:

ISSN 2526-2882

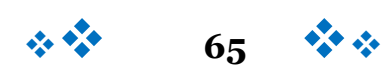


1. Desmontagem dos textos: também denominado de processo de unitarização, implica examinar os materiais em seus detalhes, fragmentandoos no sentido de atingir unidades constituintes, enunciados referentes aos fenômenos estudados.

2. Estabelecimento de relações: processo denominado de categorização, implicando construir relações entre as unidades de base, combinando-as e classificando-as no sentido de compreender como esses elementos unitários podem ser reunidos na formação de conjuntos mais complexos, as categorias. 3. Captando o novo emergente: a intensa impregnação nos materiais da análise desencadeada pelos dois estágios anteriores possibilita a emergência de uma compreensão renovada do todo. O investimento na comunicação dessa nova compreensão, assim como de sua crítica e validação, constituem o último elemento do ciclo de análise proposto. $\mathrm{O}$ metatexto resultante desse processo representa um esforço em explicitar a compreensão que se apresenta como produto de uma nova combinação dos elementos construídos ao longo dos passos anteriores.

4. Um processo auto-organizado: o ciclo de análise descrito, ainda que composto de elementos racionalizados e em certa medida planejados, em seu todo constitui um processo auto-organizado do qual emergem novas compreensões. Os resultados finais, criativos e originais, não podem ser previstos. Mesmo assim é essencial o esforço de preparação e impregnação para que a emergência do novo possa concretizar-se (MORAES; GALIAZZI 2011, p. 11-12, grifos nossos).

Assim, ao analisar os dados, podemos identificar indícios sobre como estes sujeitos entendem as TDIC e suas potencialidades para serem integradas à sua prática pedagógica. Apresentamos, a seguir, os resultados obtidos no decorrer do desenvolvimento dessa proposta de formação continuada.

\section{Reflexões a partir dos depoimentos dos professores sobre novas tecnologias}

Ao iniciar a proposta de formação continuada, a primeira atividade foi a apresentação aos professores da metodologia Webquest, suas potencialidades e suas ferramentas, isto é, seus componentes e o significado de cada um deles. Também foi explorado o PhpWebquest, apresentando várias Webquests.

Essa atividade objetivava aproximar os professores participantes fazendo com que eles socializassem suas ideias sobre as TDICs com o grupo, suas dúvidas e os problemas existentes nas escolas que trabalhavam. Vale dizer que, de posse das informações coletadas por meio da observação, as pesquisadoras escolheram o texto de Libâneo (2004) ${ }^{15}$ para o grupo realizar a leitura e discutir no próximo encontro. O texto selecionado contribuiu para os professores refletirem e poderem discutir sobre como as tecnologias são consideradas na sociedade

${ }^{15}$ LIBÂNEO, C. B. ADEUS PROFESSOR, ADEUS PROFESSORA? Novas exigências educacionais e profissão docente. $8^{\mathrm{a}}$ ed. São Paulo: Cortez, 2004. p.13-53.

ISSN 2526-2882

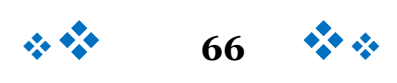


moderna, ou seja, como um "mal necessário", e ainda observar a inexistência de uma reflexão crítica sobre elas, visto que há um olhar somente para os seus aspectos positivos.

Imbernón (2009) ressalta que a formação deve "estabelecer os caminhos para ir conquistando melhorias pedagógicas, profissionais sociais, e também no debate entre o próprio grupo profissional” (IMBERNÓN, 2009, p. 110).

Assim, as teorias são fundamentais para a mudança de suas práticas pedagógicas, que são sociais e têm ingredientes estruturantes, conforme Franco (2012, p.175) afirma as “decisões, princípios, estratégias de negociação e adesão” dos professores.

Ao discutimos o texto selecionado, os professores mencionaram que há dificuldades em realizar uma formação continuada que discuta temas relacionados aos impactos das TDIC, conforme Miskulin (2006),

Os educadores devem estar abertos a essas novas formas do saber, novas maneiras de gerar e dominar o conhecimento, novas formas de produção apropriação do saber científico, pois, assim, poderiam compatibilizar os métodos de ensino das teorias de trabalho com [...] tornando-as partes integrantes da realidade do aluno (MISKULIN, 2006, p.154)

Nessa perspectiva, os professores deram início à construção da Webquest, em que cada um dos participantes seguiu os passos propostos pela metodologia. Nesse momento, para os professores sentirem-se mais confiantes e podermos tirar as possíveis dúvidas, utilizamos o datashow.

Vale dizer que nessa etapa inicial, observamos que alguns professores não sabiam acessar o e-mail e teve caso de participante que utilizou o e-mail do filho, visto que não possuía e-mail e tinha dificuldades com as ferramentas básicas do navegador.

Libâneo (2004) sublinha que os professores precisam aprender a usar as tecnologias, mas também utilizá-las para o desenvolvimento educacional, e destaca "os cursos de formação precisam garantir espaços para práticas e estudos sobre as mídias, sobre a produção social de comunicação escolar com elas e sobre como desenvolver competente comunicação cultural com várias mídias". (LIBÂNEO, 2004, p. 72)

Neste sentido, os professores construíram sua Webquest e apresentaram para o grupo, destacando as possíveis dificuldades, bem como as potencialidades que ela proporcionaria em suas aulas.

Ao término da proposta de formação continuada, indagamos os professores sobre os seus conhecimentos básicos de informática por meio de um questionário e podemos concluir que, dos quarenta e dois participantes, apenas dezoito professores apontam ter conhecimento de informática e vinte e quatro entendem que seus conhecimentos são limitados sobre o assunto. 
Cumpre lembrar que a principal dificuldade dos professores, no decorrer do curso, foi em relação ao sistema operacional. Como a formação desenvolveu-se nos Colégios Estaduais e os computadores estão com Linux, ou seja, não possuem o Windows, isso dificultou os participantes em encontrar o navegador. Também não conseguiam recortar, colar informações do site e nem salvar figuras. As observações levaram-nos a considerar que eles têm apenas uma informática básica, isto é, sabem Windows e Office. Esse fator interferiu na elaboração das tarefas necessárias para construir sua Webquest.

Os participantes também foram questionados se conheciam a metodologia Webquest. Concluímos que dois já conheciam a metodologia Webquest, quatro conheciam um pouco e trinta e seis nunca tinham visto esta metodologia. Cabe ressaltar que dois professores que conheciam da Semana Acadêmica de Matemática, que acontece anualmente na Universidade Estadual do Oeste do Paraná - UNIOESTE - Campus de Foz do Iguaçu, e terem assistido a uma comunicação de um projeto de pesquisa, denominado "Construindo Webquest para o Ensino-Apredizagem da Matemática”, que foi orientado pela Profa. Patrícia Sandalo Pereira.

Com relação às opiniões dos participantes a respeito da metodologia Webquest, ou seja, se ela pode contribuir como uma ferramenta para o aprendizado dos alunos no contexto escolar, os professores foram unânimes em afirmar que sim.

Como podemos inferir pelos fragmentos apresentados a seguir, os professores Milene, Carlos, Pedro, Edgar, Eloisa e Sonia ressaltaram com entusiasmo as possíveis contribuições dessa metodologia:

Considerando que a tecnologia está inserida de forma irredutível no mundo, e, consequentemente, na vida dos alunos, a metodologia pode e irá contribuir muito para o aprendizado dos alunos no contexto escolar, uma vez que precisamos cada vez mais procurar despertar o interesse dos nossos alunos no desenvolvimento dos conteúdos (PROFESSORA MILENE).

Com certeza, é um recurso didático útil, pois trata do trabalho com mídias didáticas, que é essencial hoje (PROFESSOR CARLOS)

Sim. Precisamos utilizar várias metodologias para que nossos alunos tenham uma boa compreensão dos conteúdos. Esta com certeza é mais uma delas. Parabéns. (PROFESSOR PEDRO).

Certamente que sim! É mais um recurso para que o professor inove suas aulas (PROFESSOR EDGAR).

Sim. É uma forma diferente de ensinar matemática para melhor acionar o interesse dos educandos pela disciplina (PROFESSORA ELOÍSA).

Com certeza. É uma maneira de tornar as aulas mais dinâmicas e atraentes. É uma forma diversificada e diferente de ensinar (PROFESSORA SONIA).

A fala dos professores reitera o que é concebido por Franco (2012), ou seja, que "[...] processos vinculados a mídia como tv, redes sociais on-line, internet, passam a ter neste atual século grande influência educacional sobre as novas gerações” (FRANCO, 2012, p. 171). Vale ainda ressaltar o depoimento das professoras Luisa e Paula que afirmam:

Com certeza. Esta irá contribuir com os professores, pois é uma metodologia muito simples para fazer, rápida para montar e super atual, o que favorece muito a interação e a participação dos alunos (PROFESSORA LUİSA). 
Sim. Este material é de fácil utilização e manuseio, podem ser criadas várias atividades facilitando seu desenvolvimento e envolvimento dos alunos com facilidade (PROFESSORA PAULA).

Essas falas fizeram-nos refletir sobre a importância da formação continuada para os professores, pois como destaca Kenski (2006)

A grande revolução no ensino não se dá apenas pelo uso mais intensivo do computador e da internet em sala de aula ou em atividades à distância. É preciso que se organizem novas experiências pedagógicas que [...] possam ser usadas em processos cooperativos de aprendizagem, em que se valorizem o diálogo e a participação permanentes de todos os envolvidos no processo (KENSKI, 2006, p. 88).

Com relação às dificuldades na realização dos passos para criação de uma Webquest, concluímos, por meio do questionário, que três dos participantes haviam encontrado dificuldades, vinte e dois relataram que não havia nenhuma dificuldade na realização da tarefa e dezessete encontram um pouco de dificuldade.

De modo geral, os participantes indicaram que o tempo e o desconhecimento da metodologia são fatores que poderão comprometer a integração desta metodologia à sua prática pedagógica. Como podemos observar nos depoimentos dos professores Sonia, Pedro, Eloisa e Carlos.

O tempo no desenvolvimento de uma tarefa (PROFESSORA SONIA). Porque era desconhecida totalmente, até conseguir entender cada etapa (PROFESSOR PEDRO).

A falta de conhecimento da metodologia (PROFESSORA ELOISA).

Como é uma ferramenta nova, levaria um tempo maior para sua familiarização, mas, de forma geral, foi bem explicado, restando apenas o interesse por nossa parte, para desenvolvermos nossas expectativas (PROFESSOR CARLOS).

A fala dos professores apresentadas anteriormente vai ao encontro da concepção de Karsenti (2012) que afirma que a principal dificuldade da inclusão das TDIC no ambiente escolar são os professores, pois eles terão que modificar totalmente suas práticas.

Outra dificuldade apontada foi o fato de não se sentirem confiantes em relação aos conhecimentos relacionados à informática, o que fez com que não conseguissem construir sua Webquest sozinhos. Esse seria um dos fatores para a não utilização em sua prática pedagógica, como podemos verificar nos depoimentos dos professores apresentados a seguir.

Quanto ao uso da informática (PROFESSORA SONIA).

Por ser a primeira vez, depois nós vamos pegando a prática (PROFESSORA ELOÍSA).

Referente ao manuseio do micro. (PROFESSOR PEDRO).

Por ter pouco conhecimento em informática (PROFESSOR CARLOS).

Neste sentido, é fundamental os professores serem desafiados a utilizar as TDIC como uma oportunidade de contribuir com o desenvolvimento educacional, visto que Borba e ISSN 2526-2882

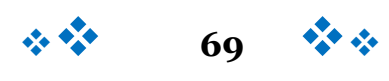


Penteado (2012) salientam que os professores, ao verificarem as possibilidades que as tecnologias podem acarretar no processo de ensino aprendizagem, entenderão que as dificuldades encontradas são possíveis de serem minimizadas.

\section{Considerações}

O desenvolvimento da pesquisa possibilitou tecer algumas considerações sobre a possível utilização da metodologia Webquest pelos professores em suas práticas pedagógicas, visto que a escola, como um ambiente social, não pode negar aos seus alunos o acesso as TDIC. Será nesse ambiente orientado pelo professor que os alunos têm a possibilidade, talvez única, de compreender as informações recebidas e também utilizar as novas tecnologias existentes.

No entanto, as TDIC serão integradas às práticas pedagógicas dos professores, se eles assim entenderem como necessárias, pois as mudanças nessas práticas não ocorrem por imposição. Como aponta Franco (2012), a mudança é um processo, pois sua estrutura é pautada na pessoa, que é o professor. Dessa forma, suas práticas pedagógicas não mudam somente se agentes externos desejam.

Sendo assim, os professores precisam de formação continuada que os veja como sujeitos possuidores de conhecimentos, e não como meros receptores de informações oriundas de especialistas. A escola necessita ser um espaço em que os professores problematizem suas práticas pautadas em teorias e também tenham acesso às diferentes pesquisas, e isso só é possível por meio da formação continuada.

No decorrer da pesquisa, observamos que os professores entendem que as TDICs precisam ser aproximadas da escola, visto que são meios que chegaram e têm potencialidades de contribuir com o desenvolvimento educacional. Cumpre lembrar que estes professores atuam na rede estadual de ensino há mais de dez anos, são preocupados com sua formação e entendem as responsabilidades em participar de propostas que contribuem com a sua atuação profissional.

Vale enfatizar que o conhecimento da metodologia Webquest favorece uma visão mais ampla dos seus limites e desafios. Porém, eles apontam que a falta de conhecimentos básicos relacionados à informática contribui para a não utilização da mesma em suas práticas pedagógicas. Outro fator destacado é o tempo para a preparação e o desenvolvimento com seus alunos, visto que as condições materiais da escola não são favoráveis. Os professores ressaltam ainda que não há uma preocupação governamental para contribuir com a inclusão das TDIC no ambiente escolar.

Conforme o referencial teórico adotado nesta pesquisa, não há como os professores utilizarem as TDIC que possibilitem um desenvolvimento educacional, se esses profissionais 
não tiverem uma formação crítica sobre estes meios auxiliares, isto é, o usar como uma mera técnica não contribuirá para o processo de ensino e aprendizagem dos seus alunos.

Enfim, a pesquisa aponta que os professores mostraram-se receptíveis e motivados para o uso da metodologia Webquest em suas práticas pedagógicas. Mas, para que isso aconteça, é fundamental que as políticas educacionais favoreçam aos professores condições que modifiquem suas práticas pedagógicas, pois a integração das TDICs no ambiente escolar pressupõe aos professores um tempo maior para estudo e preparo, bem como condições materiais em suas escolas para propor mudanças que visem à aproximação dos alunos das TDIC, propondo, de fato, o desenvolvimento educacional de qualidade.

\section{Referências}

ABAR, C. A. A. P.; BARBOSA, L. M. WebQuest: um desafio para o professor. São Paulo: Avercamp, 2008 .

BAZZO, W. A.; LINSINGEN, I. V.; PEREIRA, L. T. V. (Ed.). Introdução aos estudos CTS (Ciência, Tecnologia e Sociedade). Madrid: Organização dos Estados IberoAmericanos para a Educação, a Ciência e a Cultura, 2003. (Cadernos de IberoAmérica).

BORBA, M. C.; PENTEADO, M. G. Informática e Educação Matemática. Belo Horizonte: Autêntica Editora. 2012.

D’AMBRÓSIO, U. Educação matemática: da teoria à prática. São Paulo: Papirus, 2006

DODGE, B. Some thoughts about WebQuests, 1995. [Online]. Disponível em http://edweb.sdsu.edu/courses/edtec596/about webquests.html acessado em $23 / 03 / 2010$

FICHTNER, B. O conhecimento e o papel do professor. In. LIBÂNEO, J. C., ALVES, N. (orgs). Temas de Pedagogia: diálogos entre Didática e currículo, São Paulo: Cortez, 2012.

FRANCO, M. A. R. S. Pedagogia e prática docente. São Paulo: Cortez, 2012. p.147-172.

FULlan, M. \& HARGREAVES, A. Por que é vale a pena lutar? O trabalho de equipa na escola. Porto: Porto Editora, 2001.

GENTILI, Pablo. Desencanto e utopia: a educação no labirinto dos novos tempos. Rio de Janeiro: Vozes, 2008.

IMBERNÓN, F. A. A formação docente profissional: Formar-se para a mudança e a incerteza. São Paulo: Cortez, 2009. 
KARSENTI, T. As tecnologias da informação e da comunicação na pedagogia. In: GAUTHIER, C; TARDIF, M. A pedagogia: teorias e práticas aos nossos dias. Petrópolis: Vozes, 2012.

KENSKI, V. M. Tecnologias e tempo docente. Campinas, SP: Papirus, 2013. - (Coleção Papirus Educação)

LIBÂNEO, C. B. ADEUS PROFESSOR, ADEUS PROFESSORA? Novas exigências educacionais e profissão docente. $8^{\mathrm{a}}$ ed. São Paulo: Cortez, 2004.

LÜDKE, M. e ANDRÉ, M. E. D. A. Pesquisa em educação: abordagens qualitativas. São Paulo: EPU,1986.

MALTEMPI, M. V. Construcionismo: Um Plano de fundo para a pesquisa em informática aplicada à educação. In: BICUDO, M. A. V.: BORBA, M. C. Educação Matemática: Pesquisa em Movimento. São Paulo, SP: Cortez Editora, 2004.

MARCO, F. F. Atividades computacionais de ensino na formação inicial do professor de matemática. Campinas, SP: [s.n.], 2009.

MISKULIN, S. G. R. As potencialidades didático -pedagógico de um LEM em educação Matemática mediado pela TICs na formação de professores. In: LORENZATO, S. (org.). O Laboratório de Ensino da Matemática na formação de professores. São Paulo. Autores Associados. 2006.

MORAES, M. C. O paradigma educacional emergente: implicações na formação do professor e nas práticas pedagógicas. [on line]. Disponível em: http://twingo.ucb.br/jspui/bitstream/10869/530/1/O\%20Paradigma\%20Educacio nal\%20Emerg\%C3\%AAnte.pdf. Acessado em janeiro 2015.

MORAES, R.; GALIAZZI, M. do C.. Análise textual discursiva. $2^{\circ}$ ed. Ijuí: Unijuí, 2011.

PONTE, J. P. O Desenvolvimento Profissional do Professor de Matemática. Revista Educação Matemática, ${ }^{0}$ 31, p 9-12 e 20, 1994.

Ponte, J. P.; Oliveira, V. O contributo das tecnologias de informação e comunicação para o desenvolvimento do conhecimento e da identidade profissional. 2001. Disponível em: http://www.educ.fc.ul.pt/docentes/jponte/docs-pt/o3-PonteOli-Var(TIC-Dario).doc. Acesso em: 12 fev. 2015.

PORTO, T. M. E. As tecnologias de comunicação e informação na escola; relações possíveis... relações construídas. In: Revista Brasileira de Educação, v. 11, n..31, p. 43-57, 2006.

SANTOS, A.R. Metodologia Científica: a construção do conhecimento. Rio de Janeiro: Lamparina, 2007.

VALENTE, J. A. (Org.). O computador na sociedade do conhecimento. Campinas: UNICAMP, 1999. 
VERASZTO, E. V.; SILVA, D.; MIRANDA, N. A.; SIMON, F. O. Tecnologia, buscando uma definição para o conceito. Prisma.com n. 7, p. 60-85. 2008. Disponível em < http://revistas.ua.pt/index.php/prismacom/article/view/681/pdf $>$. Acessado em 10/05/2015.

\section{Bibliografia Resumida}

Patrícia Sândalo Pereira - Doutora em Educação Matemática pela UNESP - Rio Claro/SP. Diretora do Instituto de Matemática INMA e Docente do curso de Licenciatura em Matemática e do Programa de Pós-Graduação em Educação Matemática da Universidade Federal de Mato Grosso do Sul - UFMS. Líder do Grupo de Pesquisa Formação e Educação Matemática- FORMEM. Campo Grande - Mato Grosso do Sul - Brasil.

Currículo Lattes: http://lattes.cnpq.br/9126213537245312

Contato: patriciasandalop@uol.com.br

Susimeire Vivien Rosotti de Andrade -Doutoranda em Educação Matemática pela Universidade Federal de Mato Grosso do Sul UFMS. Mestre em Educação para a Ciência e a Matemática pela Universidade Estadual de Maringá - UEM. Docente do curso de Licenciatura em Matemática da Universidade Estadual do Oeste do Paraná - UNIOESTE - Foz do Iguaçu - PR. Integrante do Grupo de Pesquisa Formação e Educação Matemática - FORMEM. Foz do Iguaçu - Paraná - Brasil.

Currículo Lattes: http://lattes.cnpq.br/7645006700133174.

Contato: susivivien@hotmail.com 